\title{
MIGRAÇÃO, RETORNO E CIRCULARIDADE: EVIDÊNCIA DA EUROPA E ESTADOS UNIDOS
}

\author{
Sónia Pereira* \\ Sueli Siqueira**
}

\begin{abstract}
O retorno faz parte do projeto migratório, contudo, enquanto uns retornam outros permanecem. A recente crise econômica é um dos fatores que intensificou o retorno. Este artigo ilustra as dinâmicas de retorno de emigrantes brasileiros nos Estados Unidos e em quatro países europeus - Portugal, Reino Unido, Holanda e Noruega, incluindo os processos de estranhamento, adaptação e circularidade ao longo do tempo. Os dados nos permitem considerar que as condições no destino constituem um elemento central nas estratégias migratórias. Os retornados enfrentam as dificuldades de (re)adaptação no país de origem. O retorno em consequência da crise produz efeitos perversos tanto nos sujeitos como no território.
\end{abstract}

Palavras-chave: migração internacional brasileira, circularidade, retorno.

\section{Introdução}

Desde a década de 80, o Brasil tem assistido ao crescimento da população emigrada para outros países, com destaque para os Estados Unidos e alguns países europeus (Alemanha, Itália, Reino Unido, Portugal e Espanha). No entanto, as estatísticas macro dos fluxos migratórios revelam, sobretudo, as dinâmicas de saída da população, escondendo as dinâmicas de retorno, que são, também, parte integrante dos processos migratórios ${ }^{1}$. No projeto migratório está presente o desejo de ganhar dinheiro, retornar e mudar sua condição social. Muitos concretizam estes planos, enquanto outros vão

\footnotetext{
${ }^{*}$ Centro de Estudos Geográficos do Instituto de Geografia e Ordenamento do Território, Universidade de Lisboa/Portugal.

** Universidade Vale do Rio Doce, Governador Valadares - MG/Brasil.

${ }^{1}$ SAYAD, Abdelmalek. O retorno: elementos constitutivos da condição do imigrante.
} 
adiando o retorno e dando um caráter de maior permanência à sua migração, com investimentos maiores no país de destino. A recente crise econômica mundial, ao afetar negativamente o contexto econômico de vários países de destino da emigração brasileira, constituiu um dos fatores que intensificaram o retorno, nomeadamente dos EUA². No entanto, se, por um lado, o regresso ao país de origem implica em dificuldades de adaptação e desafios que podem resultar em novos projetos migratórios, por outro, o retorno não ocorre apenas em contextos de crise, como a que se vive na atualidade.

Neste artigo ilustraremos as dinâmicas de retorno de emigrantes brasileiros nos Estados Unidos e em quatro países europeus - Portugal, Reino Unido, Holanda e Noruega - desde os anos de 1980 (quando intensifica a emigração brasileira), incluindo os processos de adaptação após o retorno e a sua estabilidade. Para esta análise recorremos a um total de 61 entrevistas realizadas a emigrantes retornados nas cidades do Rio de Janeiro, Campinas e algumas cidades de Minas Gerais no âmbito do Projeto THEMIS - Theorizing the Evolution of European Migration Systems ${ }^{3}$ em 2011 e ao banco de dados do Núcleo de Desenvolvimento Regional - NEDER sobre a emigração para os Estados Unidos ${ }^{4}$.

Assim, começaremos por discutir o enquadramento teórico do papel do retorno no projeto migratório; a seguir procederemos a uma breve contextualização da emigração Brasileira nos Estados Unidos e na Europa, com especial destaque para os países em análise neste artigo; no terceiro ponto analisaremos em maior detalhe experiências diversificadas de retorno de emigrantes nos Estados Unidos e na Europa (Portugal, Reino Unido, Holanda e Noruega), com o propósito de contribuir para as tipologias de retorno existentes na literatura ${ }^{5}$. Concluiremos com uma discussão final sobre os aspectos mais relevantes do retorno de ambas as áreas geográficas.

\section{O retorno no projeto migratório}

Na perspectiva de Sayad ${ }^{6}$ a ideia ou projeto de retorno está presente na maioria dos projetos migratórios. Ou, como referem Rodrigues e Egea ${ }^{7}$ em

\footnotetext{
2 SIQUEIRA, Sueli; SANTOS, Mauro Augusto. Crise econômica e retorno dos emigrantes da Microrregião de Governador Valadares.

3 Financiado pelo programa NORFACE e coordenado pelo International Migration Institute, na Universidade de Oxford, Inglaterra.

${ }^{4} \mathrm{O}$ banco de dados de natureza qualitativa foi construído a partir de pesquisa realizada com emigrantes retornados residentes na Microrregião de Governador Valadares e dados coletados na Região da Nova Inglaterra nos Estados Unidos com emigrantes dessa região.

${ }^{5}$ CERASE, Francesco P. Expectations and Reality: a case study of return migration from the United States to Southern Italy.

${ }^{6}$ SAYAD, op. cit.

${ }^{7}$ RODRIGUEZ, Vicente; EGEA, Carmen. Return and the Social Environment of Andalusian Emigrants
} 
relação aos emigrantes da Andaluzia espanhola, "eles apenas tiveram que esperar pelo momento certo para retornar, porque tinham tomado a decisão de voltar no preciso momento em que emigraram" ${ }^{\prime 8}$. A perspectiva é, a curto ou longo prazo, um dia retornar para seu ponto de partida. Em vários fluxos migratórios, de curta ou longa distância, de trabalhadores desqualificados ou altamente qualificados, homens ou mulheres, o desejo do retorno concreto está presente, seja ele um retorno para visitar ou um retorno permanente. No entanto, durante a migração novas experiências são vividas e o projeto inicial muitas vezes é reelaborado, o retorno adiado ou abandonado. Noutros casos, pode até ser antecipado ou mesmo 'forçado' - por exemplo, por deportação nos casos mais extremos - quando o projeto migratório falha ou se verifica uma alteração nas circunstâncias do migrante (questões familiares ou problemas de saúde). O nível de agência que é exercido pelos emigrantes na formulação do seu projeto de retorno e na tomada de decisão é, assim, variável.

Nesse sentido ao longo dos quase 50 anos de experiência emigratória dos brasileiros para diversas partes do mundo muitos têm retornado, mas sob variadas formas e condições. O retorno impacta o emigrante, as pessoas com quem se relaciona e o território. O retorno pressupõe vários modos de relações: relação com o tempo (passado e futuro), relação com a terra natal nas suas dimensões física e social e ainda relação com o país que se deixou, através da manutenção de ligações (afetivas e/ou materiais) transnacionais ${ }^{9}$. Essas dimensões estão relacionadas entre si no ser social - o imigrante ${ }^{10}$.

No retorno à terra natal, além de determinantes econômicos, estão presentes outros componentes, como a necessidade de voltar às raízes para reencontrar com sua identidade, sua família e os amigos. "Para esses retornados, as vantagens sociais e culturais sobrepõem-se às vantagens econômicas encontradas fora e aos custos e muitas vezes o declínio do poder de consumo adquirido durante o período de emigração"11. Aliás, as dimensões emocional, afetiva e familiar interagem com a dimensão econômica na tomada de decisão de retornar, constituindo um elemento muitas vezes central no processo de retorno, como podemos observar nos relatos abaixo.

in Europe, p. 138.

${ }^{8}$ Tradução livre das autoras do original em inglês: "They have only had to wait for the right moment in order to return, because they had taken the decision to come back at the very moment that they emigrated".

${ }^{9}$ DE BREE, June; DAVIDS, Tine et alii. Post-return experiences and transnational belonging of return migrants: a Dutch-Moroccan case study.

${ }^{10}$ SAYAD, op. cit.

11 DeBIAGGI, Sylvia Dantas. Homens e mulheres mudando em novos espaços: famílias brasileiras retornam dos EUA para o Brasil, p. 144. 
A imigração, ela tem esse problema você ganha financeiramente, mas, afetivamente você perde muito. E a vida afetiva não tem dinheiro que compra né. [...] A gente acha que recuperou né! (risos). É um consolo né, que nós temos né, é um consolo que a gente tem. [...] mas na verdade você não recuperou. O tempo que passou, o ontem que você viveu, já não é o hoje. O hoje é hoje, e ontem é ontem, e amanhã é amanhã, eu penso assim (Mario 42 anos, emigrou para Portugal em 1999 e retornou em 2002).

[...] eu me divorciei ainda fiquei um tempo lá, um pouco da motivação pra ficar lá quer dizer, a principal motivação eu já tinha perdido né, minha mãe teve problemas de saúde sério, tava precisando da minha ajuda, então eu comecei a ficar indo e vindo pro Brasil pra cuidar da minha mãe, eu fui juntando uma coisa com a outra eu achei melhor voltar pra cá, e o mercado de trabalho também tinha melhorado, então eu vi as chances de conseguir um emprego como engenheira, isso também faz parte (Luma, 38 anos, emigrou para a Noruega em 2001 e retornou em 2007).

O retorno é o reencontro com um espaço, muitas vezes, congelado na memória, no tempo da partida. O reencontro, às vezes, resulta no estranhamento e no sentimento de não mais pertencer a este lugar, o que Hall ${ }^{12}$ chama do pecado da ausência, a impossibilidade de recuperar o tempo que não esteve presente, o não acompanhamento da dinâmica da vida neste espaço.

[...] é muito complicado, acho que os vinte primeiros dias então é um terror, porque a gente se sente um peixe fora d'água. Porque os amigos, cada um já fez sua vida, a família também não vai ficar ali o tempo todo com você. Aí acaba que você fica um pouco sem lugar, sem... eu acho que seria bom, tanto pra falar como que vai ser a chegada como a volta né. Por que é complicado (Amanda, 25 anos, emigrou para Portugal em 2008 e retornou em 2010).

É neste sentido que voltar apresenta-se para alguns mais difícil do que a decisão de partir. $\mathrm{O}$ estranhamento no reencontro com a família e em relação aos costumes, a sensação de não se reconhecer pertencente ao seu local de origem tornam-se angustiantes. O espaço geográfico e social, as pessoas idealizadas durante os anos de emigração já não são os mesmos. O migrante vivência de maneira diferenciada a situação de emigração, mesmo que o projeto tenha sido elaborado pela família ou comunidade, a experiência não é vivida de modo homogêneo por todos. As mudanças ocorrem em função das diferentes trajetórias de cada um. Alguns emigrantes

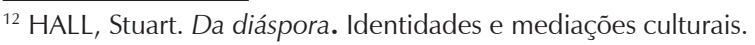


referem mesmo a importância das transformações pessoais vividas através do ato da emigração, as suas aprendizagens e as alterações que suscitam nas relações com os outros e com o espaço pré-migração.

Não, eu senti, senti ganhos não só profissionais, acadêmicos, mas pessoais, assim, que acho que você conseguir morar num país culturalmente muito diverso do seu, você sair da América do Sul e ir pra Europa e você sobreviver emocionalmente, isso é um ganho inigualável. Hoje eu posso mudar para qualquer Estado no Brasil que vai ser ridículo, assim, vai ser "fichinha" (Joana, 30 anos, emigrou para o Reino Unido em 2010 e retornou no mesmo ano).

Esses relatos corroboram para a confirmação que o retorno, dependendo do contexto e da interação do sujeito com as várias possibilidades que se lhes apresentam durante o período de emigração e o capital social de cada emigrante, se dá de modo diferenciado. No percurso de vida alguns emigrantes retornam para algum ponto, mesmo que seja fora de sua cidade de origem, outros reconstroem seu projeto e passam a viver em outro território, seja no país de destino ou outro país escolhido.

Apesar de o retorno ser constitutivo do projeto migratório pode-se afirmar que está diretamente relacionado com as condições de vida no destino. Esta influência está bem patente na tipologia do retorno apresentada por Cerase $^{13}$ com base na experiência dos italianos que retornavam dos Estados Unidos para a sua terra natal. Esta tipologia se mantém como um referencial conceptual para o estudo do retorno nas migrações internacionais. Este autor distingue: 1) o 'retorno conservador' ('return of conservatism'), 2) o 'retorno inovador' ('return of innovation'), 3) o 'retorno de aposentadoria' ('return of retirement'), e 4) 'retorno do fracasso' ('return of failure').

Nesta tipologia, o autor relaciona o projeto do retorno e a vida após o retorno com as experiências vividas no país de emigração. Assim, os tipos de retorno 'conservador' e do 'fracasso' são aqueles que aparecem mais relacionados com uma adaptação mais deficiente no país de emigração. No caso do 'retorno do fracasso', o período de estadia no destino foi curta (inferior a três anos), não permitiu a concretização do projeto migratório e resultou num regresso à vida que o migrante tinha antes da partida. No caso do 'retorno conservador', os migrantes mantêm como referência o país de origem durante a sua estadia no país de destino e é lá que investem o capital conquistado. Neste tipo o autor também inclui aqueles migrantes que alternam períodos de trabalho no destino com períodos de residência na origem.

\footnotetext{
${ }^{13}$ CERASE, op. cit.
} 
Esses migrantes retornaram definitivamente ainda durante a sua vida ativa. Por sua vez, o 'retorno de aposentadoria' é aquele que acontece depois de os migrantes terem atingido a idade de aposentar. O regresso à Itália, onde têm a sua família, com pensões dos Estados Unidos, permite-lhes um nível de vida melhor. O 'retorno inovador' refere-se ao retorno que leva para o país de origem novas ideias, valores, práticas, aprendidos no país de emigração. Estes migrantes retornam com a intenção de estabelecer novos negócios que frequentemente evidenciam as experiências vividas no exterior.

A experiência migratória brasileira encaixa-se apenas parcialmente nesta tipologia. Em primeiro lugar porque a tipologia proposta por Cerase $^{14}$ se apoia exclusivamente nas experiências de migrantes laborais e a migração brasileira contemporânea é mais diversificada, incluindo vários perfis de migrantes: estudantes, 'life-style migrants', profissionais qualificados, mulheres que casam com homens estrangeiros, para além dos migrantes laborais. Em segundo lugar, porque uma parte importante da emigração brasileira, principalmente para a Europa, é recente, poucos migrantes atingiram já a idade da aposentadoria. Até pelo contrário, a maior parte dos entrevistados regressou ao Brasil para ingressar no mercado de trabalho ou, em menor número, para estabelecer o seu próprio negócio ou, até, para retomar os estudos. E, em terceiro lugar, porque a região de origem dos migrantes estudados por Cerase é exclusivamente rural e, no caso do Brasil, predomina a presença de migrantes oriundos de zonas urbanas.

A diversificação dos perfis dos migrantes, assim como das dinâmicas espaciais da migração, que não ocorrem estritamente no sentido 'áreas rurais menos desenvolvidas para áreas urbanas mais desenvolvidas', requerem novas tipologias de retorno, mais matizadas e complexas. Simultaneamente, o Brasil apresenta-se hoje com um nível de crescimento econômico em contraciclo face ao contexto desfavorável enfrentado pelos países Europeus, principalmente no sul do continente. Consequentemente, a atratividade econômica atual do país de origem constitui uma condição única, poucas vezes explorada nos estudos do retorno, que tendem a assumir a permanência da relação de desvantagem econômica do país de origem face ao país de destino da emigração. Rodriguez e Egea ${ }^{15}$, na sua revisão dos fatores que influenciam o retorno, referem que a escala do retorno depende em grande medida das condições econômicas assim como da forma como as condições na região de origem são percebidas pelos migrantes. A atual conjuntura econômica no Brasil e na Europa é sem dúvida um fator impulsionador importante do retorno. No entanto, como veremos, a sua influência é apenas parcial.

\footnotetext{
${ }^{14}$ Ibidem.

${ }^{15}$ RODRIGUEZ, EGEA, op. cit.
} 


\section{A emigração brasileira nos Estados Unidos e na Europa}

O movimento emigratório em direção aos Estados Unidos tem início na década de 1960, tendo como origem a Microrregião de Governador Valadares, no Estado de Minas Gerais. Os emigrantes inseriram-se no mercado de trabalho secundário, inicialmente na região de New York. Ao longo das duas décadas seguintes formou-se uma rede que resultou no boom migratório da segunda metade dos anos de 1980, quando se constatou um aumento da migração brasileira para este país da ordem de 41,9\% se comparada ao período de 1960 a 1970, que foi de 1,7\% segundo dados de pesquisa realizada por Soares ${ }^{16}$. Na década de 1980 este movimento está presente, também, em outras regiões do Brasil.

Segundo os dados do Censo Demográfico de 2010, o número estimado de brasileiros residentes no exterior é de 491.645, distribuídos por 193 países do mundo. Destes a maioria se dirige para os Estados Unidos (23,8\%). Estudos realizados por Margolis ${ }^{17}$, Sales $^{18}$, Siqueira ${ }^{19}$, Assis $^{20}$ demonstram que a maioria dos brasileiros concentra-se na Região da Nova Inglaterra e na Flórida. Trabalham em atividades do mercado secundário, principalmente construção civil, serviços domésticos e jardinagem. Em algumas regiões existe uma forte presença de estabelecimentos de comércio de produtos brasileiros, roupas, cosméticos, produtos alimentícios, etc.

Uma emigração que começa na década de 1960, atinge seu ápice nos anos de 1980 e permanece, mesmo que com uma queda em seu volume, até os dias de hoje, deixa marcas tanto na origem como no destino. As localidades de grande presença da emigração brasileira são visíveis através do comércio étnico com a presença de lojas que vendem os produtos brasileiros, - exemplo a "Little Brazil", os restaurantes especializados em comidas típicas e as festas como "Brasilian Days" em New York e em Miami. Deixa também marcas invisíveis, como uma nova percepção dos nativos não só sobre estes sujeitos, mas também sobre a sua terra de origem, muitas vezes carregadas de preconceito e discriminação.

No país de origem as marcas são ainda mais fortes. Os investimentos se concretizam através de construções e abertura de novos comércios. Soares ${ }^{21}$

\footnotetext{
${ }^{16}$ SOARES, Weber. Emigrantes e investidores: redefinindo a dinâmica imobiliaria na economia valadarense.

${ }^{17}$ MARGOLIS, Maxine L. Little Brazil. Imigrantes Brasileiros em Nova York.

${ }^{18}$ SALES, Teresa. Brasileiros longe de casa.

${ }^{19}$ SIQUERIA, Sueli. Sonhos, sucesso e frustrações na emigração de retorno. Brasil/Estados Unidos.

${ }^{20}$ ASSIS, Gláucia de Oliveira. De Criciúma para o mundo: rearranjos familiares dos novos migrantes brasileiros.

${ }^{21}$ SOARES, op. cit.
} 
estuda o impacto das remessas no setor imobiliário na cidade de Governador Valadares. Segundo este autor houve uma dinamização deste setor com o surgimento de novos bairros predominando construções verticais financiadas com os investimentos dos emigrantes. Siqueira ${ }^{22}$ demonstra a dinamização do comércio com a abertura de micro e pequenos negócios em toda a Microrregião de Governador Valadares.

As notícias de trabalho bem remunerado, a chegada de caixas cheias de novidades, as fotos da beleza do país de destino não revelam as privações e as duras horas de trabalho vividas pelo emigrante. A visibilidade das construções imponentes e coloridas, ao longo dos anos, possibilitou a cristalização da ideia presente no imaginário popular de que a emigração permite, em curto espaço de tempo, realizar este sonho. Nesse processo há uma descrença nas possibilidades de mudanças e transformações sociais no seu território e a via do esforço individual, através da emigração, é a opção de mudança e realização do sonho de consumo. Por esta razão, podemos considerar que além do aspecto econômico, o território de emigração é marcado pela "cultura da emigração" que fomenta continuamente os fluxos migratórios.

Na Europa, a emigração brasileira afirmou-se sobretudo a partir dos anos 2000. Portugal constitui um dos principais destinos da emigração brasileira neste continente. São 105.622 brasileiros regulares em 2012, segundo dados oficiais do Serviço de Estrangeiros e Fronteiras - SEF²3.

Destacamos que existe uma grande disparidade dos dados relacionados à presença de brasileiros no exterior. Como vimos, segundo o Censo brasileiro de 2010 o total é de 491.645. Os principais destinos dos brasileiros na Europa foram: Portugal $(13,4 \%)$, Espanha $(9,4 \%)$, Japão $(7,4 \%)$, Itália $(7,0 \%)$ e Inglaterra/Reino Unido $(6,2 \%)$. Os dados estimados do Ministério das Relações Exteriores ${ }^{24}$ apontam um total de 3.122.813.

O fluxo para Portugal encontra-se enraizado nas ligações históricas entre os dois países, assim como na sua afinidade linguística. Entrevistas realizadas no âmbito do projeto THEMIS indicam a importância da língua na constituição de Portugal como destino da emigração brasileira. Assim, acreditando numa maior facilidade de entrada no país, comparativamente com os Estados Unidos, por exemplo, onde a obtenção de vistos e a permanência sem documentação causam maiores constrangimentos aos estrangeiros, muitos emigrantes optam por Portugal.

\footnotetext{
22 SIQUERIA, op. cit.

${ }^{23}$ SEF. Relatório de Imigração Fronteiras e Asilo - 2012, p. 17.

${ }^{24}$ MINISTERIO das Relações Exteriores, Brasileiros no Mundo: Estimativas, p. 5.
} 
O Reino Unido é também um destino recente importante para os brasileiros, apesar de os números de indocumentados não permitirem identificar com rigor a dimensão da população brasileira nesse país. Num estudo realizado em Londres, Evans et aliii ${ }^{25}$ indicam que, na grande maioria dos casos, a ida para Londres foi motivada pela busca de oportunidades de trabalho e estudo. Uma boa parte dos brasileiros (2/5) havia chegado como turistas, estando assim impossibilitados de trabalhar, mas muitos também haviam entrado no país como estudantes ou com passaporte europeu, designadamente de cidadãos italianos ${ }^{26}$.

Na Holanda, o número de brasileiros é menor, cerca de $20.426^{27}$, apesar de as informações sobre imigração irregular não permitirem um conhecimento mais rigoroso. Neste caso, são importantes as relações históricas com o Brasil (por exemplo, através da comunidade de Holambra, na região metropolitana de Campinas, onde realizamos algumas entrevistas), assim como a migração motivada pelo casamento de mulheres brasileiras com homens holandeses.

No caso da Noruega, onde a população brasileira é menor, cerca de 2.728 em 2009, nos registros noruegueses, mas 5.542 nas estimativas do Ministério das Relações Exteriores ${ }^{28}$ predominam a imigração qualificada, altamente qualificada (por exemplo, na indústria petrolífera) e aquela motivada por relacionamentos/casamentos de mulheres brasileiras com homens noruegueses.

Em Portugal ${ }^{29}$ há dados que demonstram uma importante tendência de saída dos imigrantes brasileiros, que estão regressando ao seu país de origem. Nos restantes países esta tendência é menos pronunciada, mas, como vimos, o retorno está sempre presente no processo migratório e coexiste com a chegada de novos imigrantes.

\section{A concretização do retorno: novas adaptações}

\section{A crise e o retorno dos Estados Unidos}

A crise nos Estados Unidos atinge o setor imobiliário e viveu seu ápice no ano de 2007, se instalando em diversos outros setores da economia. O mercado de trabalho secundário, principalmente, construção civil e limpeza, atividade de trabalho da maioria dos brasileiros emigrantes neste país, teve

\footnotetext{
${ }^{25}$ EVANS, Yara; TONHATI, Tânia et alii. Por uma vida melhor: brasileiras e brasileiros em Londres.

${ }^{26}$ Brasileiros com descendência italiana requerem o reconhecimento da cidadania e emigram para os Estados Unidos, pois com esse documento não necessitam de visto para entrada no país. Em países do Mercado comum Europeu podem exercer atividade laboral.

${ }^{27}$ MINISTÉRIO das Relações Exteriores, op. cit.

${ }^{28}$ Ibidem.

${ }^{29}$ Ver por exemplo notícia: <http://www.publico.pt/Local/regresso-de-imigrantes-brasileiros-afectaeconomia-de-zonas-como-a-costa-da-caparica-e-ericeira-1541357>, consultada a 07.07.2012.
} 
uma redução significativa. Para o trabalhador a crise se traduziu em redução de oferta de trabalho e redução do valor pago pela hora de trabalho. Além disso, a queda do valor do dólar em relação à moeda brasileira significou uma redução do dinheiro enviado para o Brasil. Segundo os relatos dos entrevistados, outro agravante foi o aumento da fiscalização da Imigração e o aumento da deportação. A significativa redução dos ganhos, o aumento do custo de vida e o medo muito concreto da deportação tornaram o custo benefício da emigração negativo em termos econômicos para o emigrante brasileiro.

Ficou ruim demais, eu ganhava 18 dólares a hora, depois, no final tinha que aceitar 10, teve dia que trabalhei a 8 . E tinha que dá graças a Deus quando achava, ficava até 5 dias sem nada de trabalho [...] num dava pra fechar as contas no fim do mês, o melhor era isso mesmo, volta. Aperto eu passo na minha terra mesmo, sem stress, medo e aquele sofrimento, aquele medo se ser deportado. Entrava uma pessoa diferente na loja e eu já ficava cabreiro [...], achava que era a Imigração, um desespero danado (Alberto 42 anos, mineiro, emigrou para os Estados Unidos em 2000).

[...] não tinha como pagar a casa, comer e manter o carro [...]. Eu não queria voltar sem terminar o prédio e alugar os apartamentos [...], mas pensei de tudo que é jeito e não vi saída... Quando ligava eles falava [...] 'vem não, guenta mais um pouco', mas como? O trem tava difícil demais... sem jeito mesmo, tinha jeito não. Agora taí, num sei como terminá a obra [...] penso em ir prá Portugal ...mas tô sabendo que ta difícil também... de tudo que é lado tá difícil (Juliano, mineiro, 35 anos, emigrou para os EUA em 2000 e retornou em 2009).

Ao longo dos anos, as regiões de saída dos brasileiros presenciaram também o retorno. Depois de anos de trabalho e da realização de investimentos na terra natal muitos voltam e a visibilidade destes é estampada nas casas grandes, coloridas, nos carros e mudança no padrão de vida. Os anos de privações, discriminação e trabalho duro no país de destino não são visíveis; aqueles que não obtiveram o sucesso econômico são esquecidos; porém a marca dos bem sucedidos é extremamente visível. Retornar sem demonstrar o "sucesso" do projeto migratório é extremamente penoso para o emigrante. A vergonha, o fracasso e os anos perdidos na busca do seu principal objetivo, melhorar seu padrão de vida e consumo, são evidenciados quando retornam sem a conquista tão esperada.

Em pesquisa realizada na Microrregião de Governador Valadares e seu entorno $^{30}$ o motivo de retorno declarado pela maioria dos entrevistados está

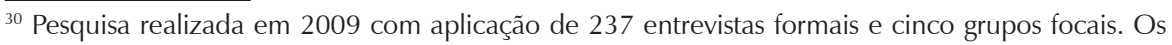


relacionado com a crise (30\%), medo de deportação e insegurança (14\%). Outros 32\% afirmam que o motivo é a saudades (30\%). Apenas 13\% afirmam que o retorno está dentro do planejamento do projeto.

As condições dos retornados variam entre aqueles que regressam com alguma perspectiva de renda e trabalho. Entre eles destacamos aqueles que fizeram investimento no Brasil (59\%), retornaram com emprego (12\%) e aqueles que voltam com capital para investir (8\%).

[...] trouxe um dinheirinho para o começo, tenho duas casas de aluguel, ela [a esposa] está trabalhando [...] eu estou aguardando ser chamado, já fiz e fui aprovado na [...] vou começar agora [...]. No começo é difícil acostumar com o trabalho aqui, mas com o tempo dá certo (Marcos, 29 anos, mineiro, emigrou para os Estados Unidos em 1999).

Destaca-se que 18\% retornaram sem saber o que fazer para auferir renda para seu sustento. Se o retorno, independente das condições, é um momento difícil e carregado de incertezas, para os que retornam sem nenhuma perspectiva é muito mais doloroso e constrangedor. Além dos objetivos traçados no projeto emigratório serem frustrados, voltam com a vergonha da demonstração deste insucesso para os seus pares.

Não ter trabalho e ficar vivendo de favor é o mais difícil. Fico com minha cabeça a mil, tem dois meses que voltei e ainda não sei o que fazer. É a pior situação que já passei...nem quando cheguei lá e não conhecia ninguém, nem sabia a língua fiquei assim, tão prá baixo... é duro viu [...] (Juarez, 42 anos, mineiro, emigrou para os EUA em 2004).

Como foi destacado por Sayad ${ }^{31}$, Hall ${ }^{32}$ e Sales $^{33}$, o retorno é parte do projeto migratório e muitos retornam não apenas por razões econômicas, mas também por razões familiares ou mesmo pela vontade de viver em sua terra natal. Estes destacam a saudades como a principal causa do retorno (32\%).

Não posso falar que a crise não me atingiu, claro, tudo ficou mais difícil, mas aqui [Brasil] também é difícil [...], eu tinha trabalho [...] não comprei casa lá [...] investi aqui, porque era aqui que eu queria viver, eu vim mesmo por causa da saudade da família, da vida e do jeito daqui [...] (Marinalda, 38 anos, mineira, emigrou para os Estados Unidos em 2003).

sujeitos da pesquisa eram emigrantes retornados dos Estados Unidos.

31 SAYAD, op. cit.

${ }^{32}$ HALL, op. cit.

${ }^{33}$ SALES, op. cit. 
Usando a tipologia de Cerase ${ }^{34}$ podemos considerar que os processos de retorno dos Estados Unidos apresentados nesse estudo encontram-se, no final dos anos 2000, majoritariamente entre o retorno conservador, envolvendo investimentos no país de origem, e o retorno do fracasso, decorrente em grande medida da deterioração das condições econômicas nos Estados Unidos, que contribuíram para a antecipação do regresso ao país de origem. Simultaneamente, identifica-se também a importância das circunstâncias familiares e da saudade como elementos importantes da constituição do retorno.

\section{Europa: migração e retorno}

Dado o caráter eminentemente recente da emigração brasileira para a Europa, as entrevistas realizadas no âmbito do projeto THEMIS permitiram captar um conjunto diversificado de perfis migratórios, incluindo não só migrantes laborais, vulneráveis à crise econômica, mas também migrantes por motivo de estudo, casamento com estrangeiros, migrantes que tinham por objetivo principal conhecer e experimentar a vida e a cultura de outro país, bem como profissionais qualificados. Consequentemente, nas entrevistas realizadas em 2011 em Campinas, no Estado de São Paulo, no Rio de Janeiro e em Governador Valadares e regiões vizinhas, no Estado de Minas Gerais, os migrantes retornados de Portugal, Reino Unido, Holanda e Noruega encontraram experiências diversificadas de retorno, que nos permitem acrescentar novas propostas à tipologia apresentada por Cerase $^{35}$, assim como ampliar o conhecimento sobre os processos de retorno.

Os entrevistados emigraram majoritariamente durante os anos 2000, mas uma percentagem importante emigrou também durante os anos 90 (14\%). A maioria regressou durante os anos 2000 e passou 2 anos ou menos fora (53\%), tratando-se portanto de migrações de curta duração. Ainda uma percentagem importante (22\%) esteve fora durante 5 ou menos anos. Salienta-se assim o reingresso da maioria no mercado de trabalho brasileiro, por oposição ao retorno por 'aposentadoria', que associa o retorno ao país de origem ao final da vida ativa.

Entre os entrevistados as experiências de vida após o retorno são diversificadas. Sem pretendermos ser exaustivas, apresentamos a seguir alguns exemplos de tipos de retorno, que permitem acrescentar complexidade aos estudos realizados anteriormente. Os tipos propostos ressoam os padrões migratórios brasileiros contemporâneos: o retorno 'life-style', o retorno planejado de estudantes e ainda o retorno antecipado por motivos familiares.

\footnotetext{
${ }^{34}$ CERASE, op. cit.

35 Ibidem.
} 
No retorno 'life-style' o tempo passado no estrangeiro é geralmente de curto ou médio prazo e é destinado a viver/experimentar o estilo de vida de outro país ou, pelo menos, esta foi a dimensão mais saliente da experiência migratória, mesmo nos casos em que a migração foi motivada por trabalho ou estudo. Habitualmente no retorno não há poupanças, nem investimento, e retoma-se a vida anterior. Até porque, frequentemente, se viveu "a vida de lá", como refere Gabriela, 30 anos, que emigrou para Portugal. As transformações vividas são sobretudo ao nível pessoal, sem grande investimento em transferências materiais para o país de origem. Em alguns casos a experiência considera-se cumprida, retornando-se com facilidade ao estilo de vida anterior. Por exemplo, no caso de Bárbara, 37 anos, que emigrou para a Holanda em 2004 e retornou em 2005.

Aí eu já tinha realizado o meu sonho de conhecer lá e tudo e eu, eu, eu optei por retomar minha vida enquanto ainda havia tempo. Eu falei assim "eu vou ficar aqui o resto da minha vida fazendo faxina, não sei até quando que eu vou aguentar"...

Noutros, a readaptação revela-se mais complicada, conduzindo a novos projetos migratórios por impossibilidade de readaptação aos valores e estilo de vida na origem, induzindo assim processos de circularidade. É o exemplo de Dinorá, que emigrou para Portugal em 2003 e regressou pela última vez ao Brasil em 2010.

Aí voltamos as duas pró Brasil, ficamos aqui 3 meses, não conseguimos ficar mais tempo. Tudo nos incomodava, a comida, nós não nos readaptamos à comida brasileira; o calor me incomodava muito, a gente não conseguiu ficar aqui. Aí voltamos pra lá, em 3 meses.

Numa atitude semelhante, Tânia, 48 anos, que emigrou para a Holanda em 2010 e regressou no mesmo ano, indica que a adaptação ao destino, a Holanda, foi mais fácil do que a tentativa de readaptação ao país de origem: "Caramba, lá eu me movimento de madrugada, eu não sinto medo, sabe, parece que a minha vida inteira eu vivi lá, eu... Hoje em dia eu me sinto uma estranha no Brasil".

Esses imigrantes retornados enfatizam, sobretudo, a sua experiência pessoal e a aquisição de experiência ou maturidade no processo migratório.

Hoje eu mudei muito depois desses quatro anos, sou outra pessoa, como se tivesse morrido e nascido de novo... quase (Luana, 33 anos, emigrou para o Reino Unido em 2007 e regressou em 2010). 
Por sua vez, o retorno planejado de estudantes enquadra-se em projetos migratórios de curto ou médio prazo que correspondem essencialmente a períodos de estudo no destino que são bem delimitados e são concretizados. É o caso de Mateus, que beneficiou de uma bolsa de doutoramento sanduíche na Noruega: "Então fiquei 2008, fevereiro de 2008 e retornei fevereiro de 2009 que era o período de bolsa de estágio doutorado sanduíche, aí desde então que eu retornei ao Brasil...".

Nestes casos, os benefícios dos períodos de estudo no estrangeiro podem ser imediatamente transpostos para um acesso em vantagem ao mercado de trabalho, como o caso de Mateus que passou a trabalhar numa empresa norueguesa no Brasil, na sequência do seu doutoramento.

No entanto, as experiências de estudo, ou trabalho, no país de destino não se traduzem imediatamente em vantagens no mercado de trabalho na origem, após o retorno. Por exemplo, Davi, 29 anos, que migrou para o Reino Unido em 2008 e regressou em 2011, apresenta o seguinte relato sobre a sua experiência de vida, bem como da aprendizagem do inglês na sua vida profissional após o retorno ao Brasil: "[...] acho que, acho que [ajuda] pouco, um pouco... Não muito, não nessa área que eu tô trabalhando".

O retorno antecipado por motivos familiares reflete, em grande medida, a alteração de circunstâncias familiares e a sua importância na constituição de processos de retorno, sendo particularmente evidentes as situações de separações de cônjuges estrangeiros que tinham motivado a migração e a necessidade de apoiar (ou acompanhar em períodos de doença) familiares no país de origem.

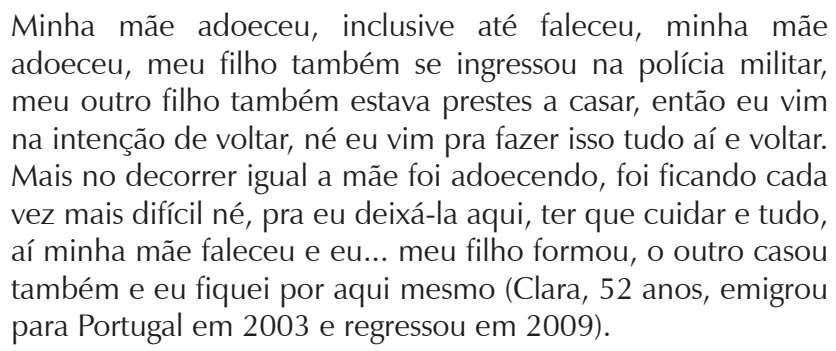

Este tipo de retorno, cuja importância foi também reconhecida no retorno dos Estados Unidos, tem sido ainda pouco explorado na literatura do retorno, mais focada na sua dimensão econômica.

Mas também encontramos exemplos de "retorno de inovação", como o da Luciana que procurou estabelecer um tipo de restaurante asiático que não havia no Brasil e que a entrevistada trouxe da Holanda. No entanto, o processo não foi fácil, principalmente devido a desentendimentos com o 
irmão que havia ficado no Brasil e era também sócio no restaurante. Com pesar informa que desistiu da sua participação no negócio. "...é muito difícil você trazer uma ideia pra cá, inovadora, e o WOK foi inovador porque não tinha" (Luciana, 57 anos, migrante na Holanda).

O retorno do fracasso envolve, em sentido abrangente, a não concretização do projeto migratório no país de destino, implicando um retorno em que o imigrante não consegue acrescentar, em termos materiais, nada à sua vivência anterior à partida. As experiências encontradas no Brasil permitem alargar o conceito definido por Cerase $^{36}$ na medida em que os objetivos migratórios são mais diversificados, incluindo, por exemplo, o desejo de estudar na Europa.

Mas nessa altura eu já estava super farta de morar lá. Porque eu não estudava, quer dizer, eu tinha 17, 18 anos... Eu só trabalhava, a minha vida era só trabalhar, e era uma coisa muito chata... E aí eu peguei o visto e vim embora, porque eu já não queria mais Portugal, eu tava detestando a vida que eu levava lá (Dinorá, emigrou para Portugal em 2003 e regressou pela última vez ao Brasil em 2010).

Como nos Estados Unidos, a crise econômica na Europa potenciou, em grande medida, o fracasso do projeto econômico, mas outros fatores influenciam também o sucesso material da migração. Os relatos a seguir ilustram bem como as próprias condições no mercado de trabalho no destino podem frustrar e impedir a concretização de poupanças, investimentos na origem ou progressão profissional, para além da crise. Simultaneamente, é importante a percepção de haver atualmente melhores oportunidades de trabalho no Brasil do que na Europa.

Um dos motivos é a crise... O pessoal não tem emprego, o mercado interno tá muito fraco, isso já tá há algum tempo, eu, profissionalmente, dentro da onde eu tava trabalhando, não tinha mais onde crescer, não tinha mais um cargo que eu desejasse tanto, porque eu já tinha sido promovido e depois fui despromovido... e o Brasil, em termos de economia, pelo menos na teoria, tava crescente... (Francisco, emigrante em Portugal).

[...] eu cheguei à conclusão que eu tava andando em círculos lá... A gente tinha uma vida classe média normal lá... a gente tava muito tranquilo lá, a gente pagava nossas contas... não sobrava dinheiro pra mandar pra cá. Não adianta, porque não sobrava. Mas também não tava passava necessidade, vivia muito bem, comia muito bem (Andrea, emigrante em Portugal).

\footnotetext{
${ }^{36}$ Ibidem
} 


\section{Para além do retorno: a questão da migração circular}

Cada vez mais, os estudiosos das migrações, em particular os que abordam as práticas transnacionais, vêm reconhecendo que o retorno não necessita de ser encarado como o fim do projeto migratório ${ }^{37}$. Nas sociedades contemporâneas, a fluidez dos fluxos migratórios, bem como a facilidade de comunicação e transporte entre países de origem e de destino, conduzem a que práticas de va-et-vient sejam crescentemente adotadas pelos migrantes, mesmo após a aposentadoria, quando todas as condições e expectativas apontariam para um retorno definitivo ${ }^{38}$. Esta opção pela migração circular, envolvendo retorno temporário e manutenção de uma ligação aos países de emigração e correspondente estilo de vida, envolve vários fatores: pode servir para atenuar sentimentos de estranhamento e dificuldades de reintegração no país de origem ${ }^{39}$, garante o acesso ao nível de rendimentos do país de destino, quando o regresso à origem não o permitiria (por exemplo, devido a restrições impostas pelos regimes de segurança social) e assegura, também dessa forma, a manutenção do envio de remessas e manutenção de famílias (mais ou menos alargadas) no país de origem (entre outros).

No caso da migração brasileira para os Estados Unidos e a Europa também encontramos alguma evidência de migração circular associada a processos de retorno temporários.

\section{Migração circular Brasil - Estados Unidos}

Ao longo das últimas três décadas de emigração de brasileiros para os Estados Unidos o retorno e as marcas desse movimento estão presentes e visíveis no território. Muitos retornam e permanecem na terra de origem, enquanto outros estabelecem um movimento de circularidade, por razões familiares, trabalho e mesmo por definir os dois espaços como lugares para viver. A trajetória de Madalena, Carol e seus companheiros Pedro e Rogério demonstram como a circularidade passou a fazer parte de suas vidas.

Madalena ${ }^{40}$ é uma senhora de 70 anos de idade que não foi além da oitava série do ensino fundamental. Trabalhou desde os 14 anos de idade como doméstica. Casou aos 21 anos e teve duas filhas e depois de casada começou a trabalhar em casa como costureira. Ficou viúva aos 32 anos.

\footnotetext{
${ }^{37}$ HUNTER, Alistair. Theory and practice of return migration at retirement: the case of migrant worker hostel residents in France, p. 184.

${ }^{38}$ Ibidem.

${ }^{39}$ BLACK, Richard; KING, Russel. Editorial introduction: migration, return and development in West Africa, p. 80.

${ }^{40}$ Entrevista realizada em 2011 numa cidade da Microrregião de Governador Valadares.
} 
A vida era difícil, ele (marido) não deixou nada [...] trabalhava como doida na máquina e não dava pra pagar tudo no fim do mês [...] num tinha casa, vivia de aluguel [...] num gosto nem de lembrar, era muita pobreza [...].

A alternativa de migrar para os Estados Unidos surgiu quando uma vizinha retornou a passeio para visitar a família e se dispôs a ajudá-la na documentação. Conseguiu emigrar com documentos falsos.

[...] me ajudou demais, devo tudo a ela. Num tinha dinheiro pra pagar nada, ela pagou tudo e depois eu paguei aos pouquinhos pra ela. Lá, abaixo de Deus foi ela que me ajudou em tudo. Num sabia nada [risos] num sabia nem pedir comida, sem ela ia morrer de fome.

Madalena deixou as duas filhas com a irmã e emigrou com a amiga para a cidade de Newark no estado de Connecticut (EUA). Começou a trabalhar como costureira em uma fabrica onde trabalha até hoje.

Cheguei e fui trabalha lá [...] tem 32 anos que estou lá, já mudou de dono e eu ainda tô lá. [...] lá tem muitas brasileiras, mexicanas, peruanas [...]. Ganha menos do que faxina, sim, mas pra mim foi melhor, num sei falar inglês, é! Até hoje num sei, mas sei umas palavrinhas que dá pra si virá.

Depois de seis anos, Madalena conseguiu o Green Card e levou as duas filhas. A mais velha mora em Newark, casou, tem duas filhas e está documentada. A mais nova depois de dois anos retornou para o Brasil, casou-se, tem dois filhos. Madalena investiu em sua cidade de origem, comprou um lote e construiu um prédio de três andares com 6 apartamentos e uma loja de comércio na frente. Um apartamento é ocupado pela filha e outro ela mantém para seu uso quando vem ao Brasil. Possui também uma casa em Newark que dividiu em três moradias. Aluga duas e reside em uma.

Agora eu venho todo ano, fico dois ou três meses aqui [Brasil]. Não aguento mais o frio. [...] sabe, eu num sei se um dia eu vou ficar aqui, acho que não [pausa]. Eu gosto assim, lá e aqui. Sabe tem a [filha] que mora lá [EUA] e num vem pra cá pra vive, então eu acho que vai ficar assim, até eu aguentar.

Madalena vive uma vida em dois lugares. Ela possui filhas, netos, sobrinhos e amigos nesses dois territórios. Depois de mais de trinta anos de trabalho tem seus investimentos nos dois lugares e ir e vir é um movimento natural em sua rotina. Programou sua festa de 70 anos no Brasil com a presença das duas filhas, mas fez também uma festa na cidade de Newark, pois afirma: 
"Num tinha jeito de num fazer lá também, e os amigos e os parentes, tem gente lá e aqui que eu queria que comemorasse comigo, então fiz duas [risos]".

Outro caso interessante que mostra a circularidade desse movimento migratório em suas várias facetas é retratado pelo casal Carol e Pedro. Carol emigrou com os pais, aos 14 anos, cursou a High School na cidade de Bridgeport e quando os pais decidiram retornar para o Brasil ela resolveu ficar, mesmo sem ter a documentação necessária para viver nos Estados Unidos. Casou com Pedro, um português que vivia nos Estados Unidos há mais de 15 anos. Como Pedro era documentado Carol conseguiu seu Green Card. Ela trabalha como house cleaner e Pedro é sócio de uma loja de revenda de parabrisa de carros. Com o nascimento da filha decidiram passar uns tempos no Brasil. Construíram um apartamento no térreo da casa dos pais de Carol.

Quando a Camilinha nasceu eu fiquei querendo minha família por perto, assim, eu quero que ela viva com os primos, os avós, os tios. O problema é que tudo é longe. Portugal, Estados Unidos e aqui. [...] difícil, difícil [...], então a gente está fazendo assim, fica um pouco aqui, um pouco em Portugal e um pouco nos Estados Unidos. Lá é que a gente ganha dinheiro, então, tenho que viver lá também, mas quero ter minha casa aqui. Ele também quer ter a casa lá [Portugal]. Um ano a gente vai prá lá [Portugal]. Fica dois ou três meses e no outro vem pra cá [Brasil].

Esse casal possui residência, família e amigos em diferentes territórios, divide seu cotidiano, ao logo do ano, nesses diferentes espaços, circulando entre Estados Unidos, Portugal e Brasil.

[...] nem penso nisso, se ficar no Brasil vamos sentir falta de tudo que a gente tem lá [...] as coisas, a vida, os amigos e o trabalho, já acostumei com o jeito de lá [EUA] de trabalhar [...]. Ele sente falta de Portugal, dos pais dele, dos amigos, é muito apegado a tudo lá [...] eu também gosto de lá [Portugal].

Conforme relato de Carol, a vida vivida em três diferentes lugares é a mais confortável, pois eles não conseguiram escolher um desses territórios como o local definitivo de moradia. A definição de um espaço significaria perdas.

Outro caso que demonstra uma circularidade não só de indivíduos, mas de famílias é o do emigrante João ${ }^{41}$. Ele emigrou em 1986, tinha 22 anos e o segundo grau completo. Através de amigos conseguiu se estabelecer na região de Boston trabalhando em restaurantes. Em 1994 conseguiu seu Green Card e abriu seu restaurante. Todo ano vinha ao Brasil visitar a família.

\footnotetext{
${ }^{41}$ Entrevista realizada em 2007.
} 
Conheceu e se casou com uma moça de sua cidade que foi viver com ele nos Estados Unidos. Tiveram três filhos que periodicamente vinham passar férias no Brasil. Em 2001 construiu um hotel em sua cidade de origem e passou, juntamente com a mulher e dois irmãos, a dividir seu tempo entre os negócios no Brasil e nos Estados Unidos. Atualmente um de seus filhos estuda no Brasil e os outros dois nos Estados Unidos. Ele a esposa, os filhos e os irmãos vivem não entre os dois lugares, mas nos dois lugares, pois possuem atividade econômica, relações afetivas e sociais nesses dois espaços.

Esses casos nos permitem compreender que o retorno, em muitas circunstâncias, não é o fim do projeto migratório ${ }^{42}$, mas muitas vezes a sua continuidade. As várias nuances do retorno na perspectiva do fenômeno migratório contemporâneo demonstram que origem e destino se constituem num circuito integrado ou num movimento de circularidade.

\section{Migração circular Brasil - Europa}

A emigração contemporânea do Brasil para a Europa distingue-se pela idade jovem dos emigrantes, pela importância da procura de experiências culturais, profissionais e novos estilos de vida, por relacionamentos desenvolvidos com pessoas de outros países e também pela importância dos projetos de migração de curto ou médio prazo. É por isso possível que, após uma primeira migração, se constituam novos projetos migratórios ou circularidade na migração. No entanto, é importante mencionar que, apesar de presente, este tipo de mobilidade foi secundário em face de casos de retorno com caráter mais permanente, mesmo que inicialmente o regresso não tenha sido percebido como tal, como relata Sara antiga emigrante de Minas Gerais no Reino Unido: "Agora dessa segunda vez que eu vim que eu sabia mesmo, sabia e não sabia, achava que eu ia ficar um ano, seis meses, mas ainda tô aí né (risos)".

Uma das razões apontadas para a nova re-emigração consiste precisamente no estranhamento vivenciado após o retorno ao estilo de vida do país de origem, que passa a ser contrastado com o do país de emigração. Evidenciam-se assim as dificuldades de re-adaptação como a origem de nova migração. Este é o caso de Dinorá e sua irmã, já anteriormente mencionado ${ }^{43}$.

Neste caso, a re-emigração apresentou-se como uma solução possível face às condições individuais e familiares, mas também face ao enquadramento estrutural, designadamente pela facilidade do movimento para o mesmo destino anterior (Portugal). A entrevistada regressou novamente ao Brasil em

\footnotetext{
${ }^{42}$ HUNTER, op. cit.

${ }^{43}$ Ver na página 129.
} 
2010, mantendo-se incerto se se trata de um retorno permanente ou se poderão se constituir novos projetos migratórios, nomeadamente se surgir alguma proposta de trabalho atraente. Neste caso, segundo Dinorá: "Não pensava duas vezes! Voltava!". Por sua vez, Bárbara, migrante na Holanda, indica que apesar de ter gostado de viver no país, não voltaria irregular, consistindo a falta de acesso legal à mobilidade uma barreira à constituição de uma nova emigração para esse país e a uma eventual circularidade na migração. Em ambos os casos as ligações ao anterior país de emigração são mantida, principalmente pelo contato com familiares que ainda lá estão (mãe, no primeiro caso, irmão, no segundo).

Outra situação, também descrita, consiste na constituição de circularidade nos relacionamentos mantidos com nacionais de outro país, como Pierina, que já passou várias temporadas na Holanda devido a um namorado holandês, havendo a expectativa de se mudar em definitivo num futuro próximo.

\section{Considerações finais}

A complexidade dos fluxos migratórios internacionais atuais indica que a alteração dos perfis dos emigrantes - que incluem, para além dos migrantes laborais ou de reagrupamento familiar, também profissionais qualificados, estudantes, aqueles que procuram experimentar a vida e a cultura de outro país ou casamentos internacionais - introduziu também complexidade nos processos de retorno. Simultaneamente, os contextos macroeconômicos nos países de destino e origem não se podem assumir como estáveis ou cristalizados. A posição econômica atual do Brasil é uma clara evidência de como a posição relativa das condições macroeconômicas nos países de destino e origem podem se alterar.

Neste sentido, se por um lado existe continuidade na ideia de retorno nos projetos migratórios, por outro, as características desse retorno, quer na formulação dos projetos, quer na reinserção no país de origem, mostram-se mais complexas e matizadas, contrariando a primazia do 'econômico' nos processos migratórios.

Nesta ótica, encontramos uma grande relevância dada às alterações das circunstâncias familiares ou à dimensão afetiva e emocional na antecipação do retorno, ainda pouco exploradas do ponto de vista teórico-conceptual nos estudos das migrações. Também destacamos o retorno life-style, no qual é a concretização da experiência da migração, do viver, experimentar e por vezes estudar num outro país que determina o retorno. Nestes casos, o ganho pessoal tende a superar a experiência material, que muitas vezes é pouco compensatória. Sendo assim, a aquisição de outros estilos de vida torna por vezes difícil a readaptação na origem, conduzindo a retornos temporários e à 
formulação de novos projetos migratórios, conduzindo à circularidade. Outro aspecto a ressaltar é o retorno planejado dos estudantes, que cumprem o seu plano de estudos no exterior e regressam, por vezes com benefícios para a sua trajetória profissional no país de origem.

Há, também, experiências mais 'clássicas', já bem identificadas na literatura, como os processos difíceis associados ao retorno de inovação ou o retorno do fracasso, intensificado no âmbito das crises econômicas nos países de destino, que limitam a plena concretização dos objetivos materiais associados à migração, mas que também têm a ver com as próprias condições do mercado de trabalho nos países de destino.

Existe assim uma necessidade de os estudiosos das migrações e do retorno dedicarem mais atenção às múltiplas dimensões que estruturam o retorno, quer do ponto de vista econômico, quer na vertente pessoal, familiar e afetiva, assim como alargarem a análise a vários perfis de emigrantes, para além dos migrantes laborais e suas famílias. As dinâmicas territoriais nas regiões de origem dos emigrantes deverão ser também merecedoras de atenção, ainda que não tenha sido possível explorá-las no âmbito deste artigo.

\section{Bibliografia}

ASSIS, Gláucia de Oliveira. De Criciúma para o mundo: rearranjos familiares dos novos migrantes brasileiros. Florianópolis: Editora Mulheres, 2011.

BLACK, Richard; KING, Russel. Editorial introduction: migration, return and development in West Africa. Population, Space and Place, v. 10, n. 2, 2004, p. 75-83.

CERASE, Francesco P. Expectations and Reality: a case study of return migration from the United States to Southern Italy. International Migration Review, v. 8, n. 2, 1974, p. 245-262.

DE BREE, June; DAVIDS, Tine et alii. Post-return experiences and transnational belonging of return migrants: a Dutch-Moroccan case study. Global Networks, v. 10, n. 4, 2010, p. 489-509.

DeBIAGGI, Sylvia Dantas. Homens e mulheres mudando em novos espaços: famílias brasileiras retornam dos EUA para o Brasil. In DeBIAGGI, Sylvia Dantas; PAIVA, Geraldo José (orgs.). Psicologia, E/Imigração e cultura. São Paulo: Casa do Psicólogo, 2004, p. 135-164.

EVANS, Yara; TONHATI, Tânia et alii. Por uma vida melhor: brasileiras e brasileiros em Londres, 2010. Londres: Grupo de Estudos sobre Brasileiros em Londres, 2010.

HALL, Stuart. Da diáspora. Identidades e mediações culturais. Belo Horizonte: UFMG, 2003.

HUNTER, Alistair. Theory and practice of return migration at retirement: the case of migrant worker hostel residents in France. Population, Space and Place, v. 17, n. 2, 2011, p. 179-192. 
Migração, retorno e circularidade: evidência da Europa e Estados Unidos

MARGOLIS, Maxine L. Little Brazil. Imigrantes Brasileiros em Nova York. Campinas: Papirus, 1994.

MINISTÉRIO das Relações Exteriores. Brasileiros no Mundo: Estimativas, 2011.

RODRIGUEZ, Vicente; EGEA, Carmen. Return and the Social Environment of Andalusian Emigrants in Europe. Journal of Ethnic and Migration Studies, v. 32, n. 8, 2006, p. 1377-1393.

SAYAD, Abdelmalek. O retorno: elementos constitutivos da condição do imigrante. Travessia, número especial, 2000.

SALES, Teresa. Brasileiros longe de casa. São Paulo: Cortez, 1999.

SEF. Relatório de Imigração Fronteiras e Asilo 2012. Barcarena, 2013. Disponível em: $<$ http://sefstat.sef.pt/Docs/Rifa\%202012.pdf>.

SIQUERIA, Sueli. Sonhos, sucesso e frustrações na emigração de retorno. Brasil/ Estados Unidos. Belo Horizonte: Argvmentvm, 2009.

SIQUEIRA, Sueli; SANTOS, Mauro Augusto. Crise econômica e retorno dos emigrantes da Microrregião de Governador Valadares. Travessia - Revista do Migrante, n. 70, janeiro - junho 2012, p. 27-47.

SOARES, Weber. Emigrantes e investidores: Redefinindo a dinâmica imobiliária na economia valadarense. Dissertação (Mestrado em demografia). Universidade Federal do Rio de Janeiro. Rio de Janeiro, 1995.

\section{Abstract}

\section{Migration, return and circularity: evidence from Europe and the United States}

Return is part of the migratory project, however, while some migrants return others remain. The recent economic crisis is one of the factors that intensified return. This article illustrates the return dynamics of Brazilian immigrants in the United States and four European countries - Portugal, UK, the Netherlands and Norway -, including processes of estrangement, circularity and adaptation over time. The data allow us to conclude that conditions in the destination country are a decisive contribution to migration strategies. Returnees face difficulties of (re) adaptation in the origin country. The return due to the crisis produces perverse effects both in subject and in the territory.

Keywords: brazilian international migration, return, circularity.

Recebido para publicação em 30/08/2013.

Aceito para publicação em 21/11/2013.

Received for publication in August, 30 ${ }^{\text {th }}, 2013$. Accepted for publication in November, 21 th 2013.

ISSN impresso: 1980-8585

ISSN eletrônico: 2237-9843 